\title{
La Cova dels Jurats de Calescoves (Alaior, Menorca). ¿Un santuario rupestre en el mundo Talayótico?
}

\author{
Cova dels Jurats at Calescoves (Alaior, Minorca). \\ A Cave Shrine in the Talayotic context?
}

\author{
Elena SÁnchez LóPez*, Margarita Orfila Pons**, Mario Gutiérrez Rodríguez***, \\ Purificación MARÍN DÍAZ**** \\ * Universidad de Granada. Departamento de Prehistoria y Arqueología, Facultad de Filosofía y Letras, Granada. \\ elenasanchez@ugr.es \\ ** Universidad de Granada. Departamento de Prehistoria y Arqueología, Facultad de Filosofía y Letras, Granada. \\ orfila@ugr.es \\ *** Universidad de Granada. Departamento de Prehistoria y Arqueología, Facultad de Filosofía y Letras, Granada. \\ mgrodriguez@ugr.es \\ **** Universidad de Granada. Departamento de Prehistoria y Arqueología, Facultad de Filosofía y Letras, Granada. \\ purimarindiaz@gmail.com
}

Recibido: 10-11-2015

Aceptado: 13-07-2016

\begin{abstract}
RESUMEN
Las excavaciones llevadas a cabo entre 2010 y 2012 en la Cova dels Jurats han permitido determinar que, a diferencia del resto de las cuevas de Calescoves, todas ellas de enterramiento, ésta funcionó como santuario, distinguiéndose dos fases diferentes en su uso. La primera se corresponde con el periodo Talayótico Final, convirtiéndose en el primer santuario rupestre documentado en la cultura talayótica, tanto menorquina como mallorquina. Ya en época romana, el lugar sigue funcionando como santuario, aunque con un ritual totalmente diferente, al que se asocian las inscripciones descubiertas a la entrada de la cueva.
\end{abstract}

Palabras Clave: Arqueología Talayótica, Arqueología Púnica, Arqueología Romana, Islas Baleares, Cueva, Santuario.

\begin{abstract}
Excavations carried out in the Cova dels Jurats between 2010 and 2012 served to establish that, unlike the rest of the caves Calescoves, this one functioned as a sanctuary, with two different phases. The first one corresponds to the Late Talayotic Period, as the first cave shrine documented in the Talayotic culture. In Roman times, the place was still used as a sanctuary, but with a totally different ritual, linked to the inscriptions discovered at the entrance of the cave.
\end{abstract}

KeYwords: Talayotic Archaeology, Punic Archaeology, Roman Archaeology, Balearic Island, Cave, Sanctuary.

Sumario: 1. Introducción. el conjunto arqueológico de Calescoves. 2. Cova dels Jurats o de l’Esglesia. 3. Excavación arqueológica en el interior de la Cova dels Jurats. 4. Registro cerámico de la Cova del Jurats. 5. Cronología y usos de la Cova dels Jurats. ¿Un santuario rupestre Talayótico? 


\section{Introducción. El conjunto arqueológico de Calescoves}

La ensenada natural de Calescoves, en la costa sur de la isla de Menorca, está formada por la conjunción de tres barrancos que, de este a oeste, son: Lloc Nou d'es Fasser, Biniadris y Sant Domingo. Son concretamente dos de ellos, los de Biniadris y Sant Domingo, los que le confieren su peculiar forma, semejante a una "Y", con dos fondos y una sola boca de entrada. Esta configuración es lo que hace de Calescoves un lugar abrigado, factible de ser utilizado como fondeadero en los meses de estío y sobradamente conocido, desde la Antigüedad, como puerto idóneo para el refugio de pequeñas embarcaciones. A ello se suma la existencia de manantiales de agua potable situados a nivel del mar, lo que convierte la cala en un interesante punto de aguada (Fig. 1).

El acceso a este paraje desde los barrancos mencionados permite una fácil conexión entre ese punto de la costa y el interior de la isla. Esto añade otra ventaja a la ensenada, pues permite transportar con facilidad los bienes que pudieran ser desembarcados hasta los poblados talayóticos de Sont Rotger, Biniadris/Lloc Nou d'es Fasser, Binicalaf, So Na Caçana o Torre Llisà (todos ellos a menos de $5 \mathrm{~km}$ de Calescoves) (Orfila et al. 2015).

Pero además, esta cala acoge una amplia selección de elementos arqueológicos de diversa índole (Orfila et al. 2010; Orfila et al. 2015). Para empezar, hay que destacar el casi centenar de cuevas artificiales recortadas en sus acantilados, que conformaron una gran necrópolis protohistórica hipogéica, fechada entre los siglos IX y II a.C. (Veny 1982; Gornés y Gual 2000; Gornés 1997 y 2000). Desde inicios del siglo XIX se menciona la fortificación conocida como Es Castellet (Rámis 1817; Veny 1982; Sánchez et al. 2013), en la que se habilitó un pozo con escalera de acceso a su interior (Veny 1982; Plantalamor 1991a). Lo mismo sucede con la serie de paneles epigráficos de época romana ubicados justo en la entrada de la Cova dels Jurats o de l'Església (Ramis 1817; Veny 1965; Orfila et al. 2010; Orfila et al. 2013; Mayer 2015). A mediados del siglo XX se documentó, además, otra función durante la Antigüedad para esta ensenada, que fue utilizada como fondeadero desde el siglo V a.C. hasta la época

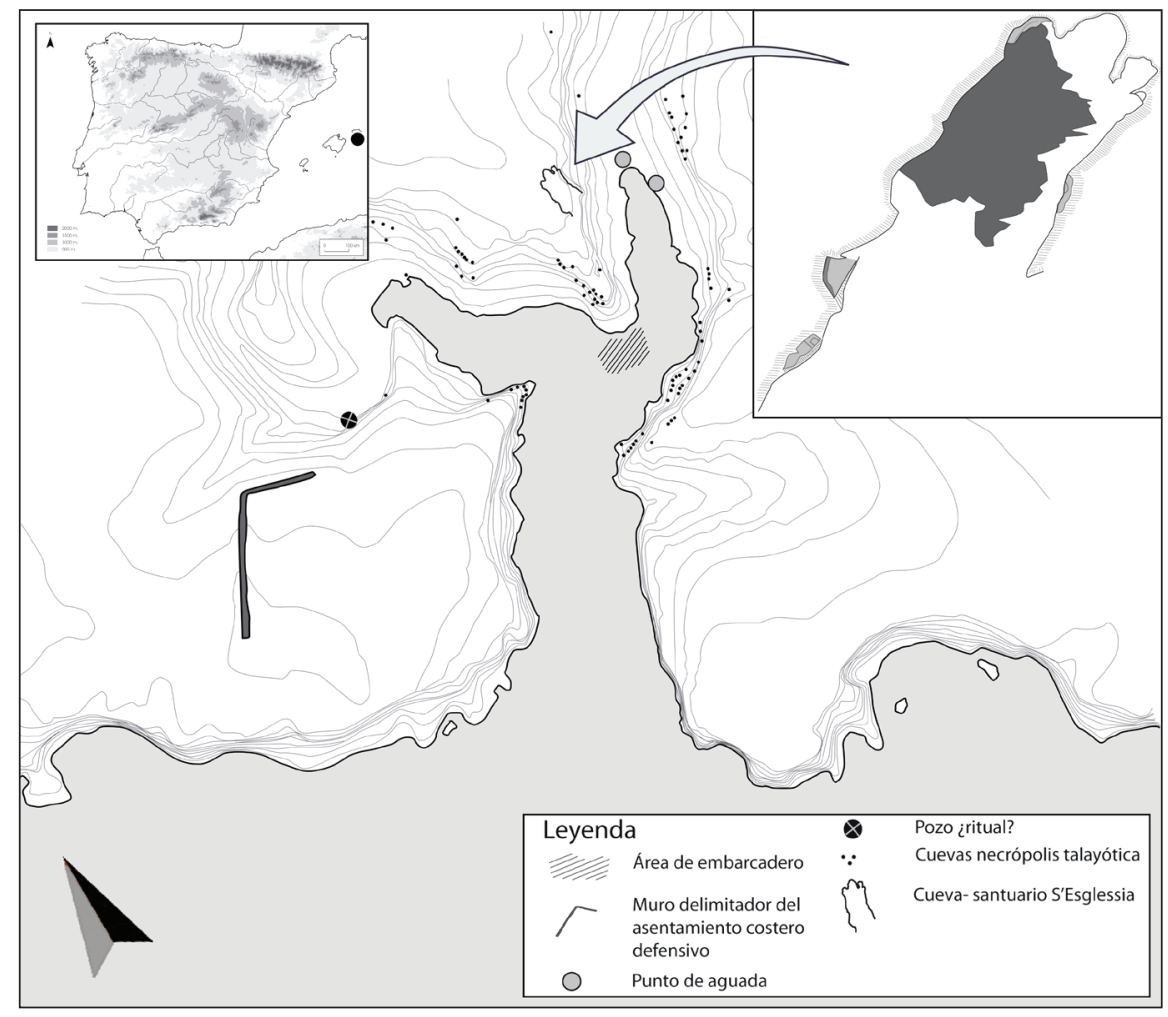

Figura 1. Conjunto Arqueológico de Cales Coves. 
bajo imperial (Fernández-Miranda et al. 1977; Belén y Fernández-Miranda 1979; FernándezMiranda y Rodero 1991). La Cova dels Jurats ha sido analizada por un proyecto reciente, dirigido desde las universidades de Granada, Macerata y Barcelona, que ha procurado un estudio epigráfico y arqueológico del conjunto (Orfila et al. 2010; Orfila et al. 2013; Orfila et al. 2015; Sánchez y Orfila 2015).

\section{Cova dels Jurats o de l'Esglesia}

\section{La estructura del conjunto}

La gruta, cuyo acceso, junto a la pared con los paneles inscritos, está casi completamente obstruido por las enormes piedras desprendidas del techo, presenta una planta alargada y tripartita, ya que parece formar tres "ábsides" en su extremidad interior. El origen del topónimo Cova de l'Esglèsia debe seguramente estar relacionada con esta particular estructura interna.

$\mathrm{Al}$ exterior de la cueva, en la zona más cercana al acceso actual de la misma, se han documentado, sobre una repisa situada a aproximadamente $1,60 \mathrm{~m}$ respecto al nivel actual de circulación, tres encajes bien recortados. En relación a la funcionalidad de los mismos, se ha propuesto la colocación de un número correspondiente de esculturas relacionadas con el área sacra rupestre (Orfila et al. 2010; Orfila et al. 2013; Orfila et al. 2015), aunque por el momento, no se han hallado restos del material escultórico. Esa configuración es la que hizo que también se conociera como "dels Jurats", a asociarse esos encajes con posibles asientos de magistrados.

Junto a esta repisa, y en dirección a la cueva, se desarrollan los epígrafes por los que es bien conocida la Cova dels Jurats. El conjunto, formado actualmente por los restos de 29 inscripciones, debió ser mucho más amplio en la Antigüedad. En todas ellas aparece reiteradamente la alusión a la fecha en la que se celebraban los Parilia, lo que podría vincularlas a una celebración del nacimiento de Roma. Las inscripciones se fechan entre el 125 y el 230 dC. (Orfila et al. 2010; Orfila et al. 2013).

\section{El interior de la gruta}

La cueva conocida como Cova dels Jurats o de l'Església, no había sido explorada nunca en su interior de manera sistemática, aunque a través de la bibliografía se tenía alguna referencia sobre la recuperación de materiales cerámicos de su subsuelo. Más concretamente, se sabía de varios cuencos de cerámica megárica procedentes de ese lugar, datados en torno al sigo II a.C. (Belén y Fernández-Miranda 1979: 126, Fig. 13 n 1, 2 y 3 ). Esto, unido a las referencias transmitidas por vía oral de la recuperación de otras cerámicas, hacía probable la existencia de potencial arqueológico. Es por ello que uno de los objetivos prioritarios del proyecto que se desarrolló entre 2010 y 2012 fuera hacer una excavación arqueológica sistemática en el interior de la gruta. Paralelamente se llevó a cabo el levantamiento topográfico, puesto que tampoco existía un plano de la misma (Orfila et al. 2010).

Los resultados de estos trabajos permiten hoy afirmar que esta gruta, de origen natural y con retoques antrópicos, tiene un tamaño y forma totalmente diferente del resto de las cuevas horadadas artificialmente en los acantilados de la cala (Obrador 2015). De unos $20 \mathrm{~m}$ de profundidad y unos 9 de anchura, su altura original debió oscilar entre 4 y 5 metros, características a las que se añaden la particularidad de presentar una estructura de triple ábside en el extremo opuesto al de su acceso.

En el centro de la cueva, en lo que parece ser el "ábside central", pudo tal vez colocarse algún tipo de elemento o figura de culto, hipótesis vinculada a la presencia de unos agujeros en el suelo de roca y al rebaje de la pared de fondo (Orfila et al. 2015: 71). En el "ábside derecho", en cambio, se excavó una posible piscina circular o lacus de $120 \mathrm{~cm}$ de diámetro, en la cual podía ser recogida el agua de infiltración que discurría por las grietas y fracturas naturales de la roca (Orfila et al. 2015: 71). El "ábside" situado a la izquierda, no ha sido excavado y sólo parcialmente revisado, ya que se encuentra obstruido y cubierto por el material detrítico desprendido del techo de la cueva.

A lo largo de las paredes de la cueva se han identificado varias repisas en forma de bancadas, en algún caso de considerables dimensiones. Asimismo son visibles nichos recortados artificialmente para el alojamiento de lucernas.

\section{Excavación arqueológica en el interior de la Cova dels Jurats}

Las intervenciones realizadas en las tres campañas de excavación han permitido señalar que el 


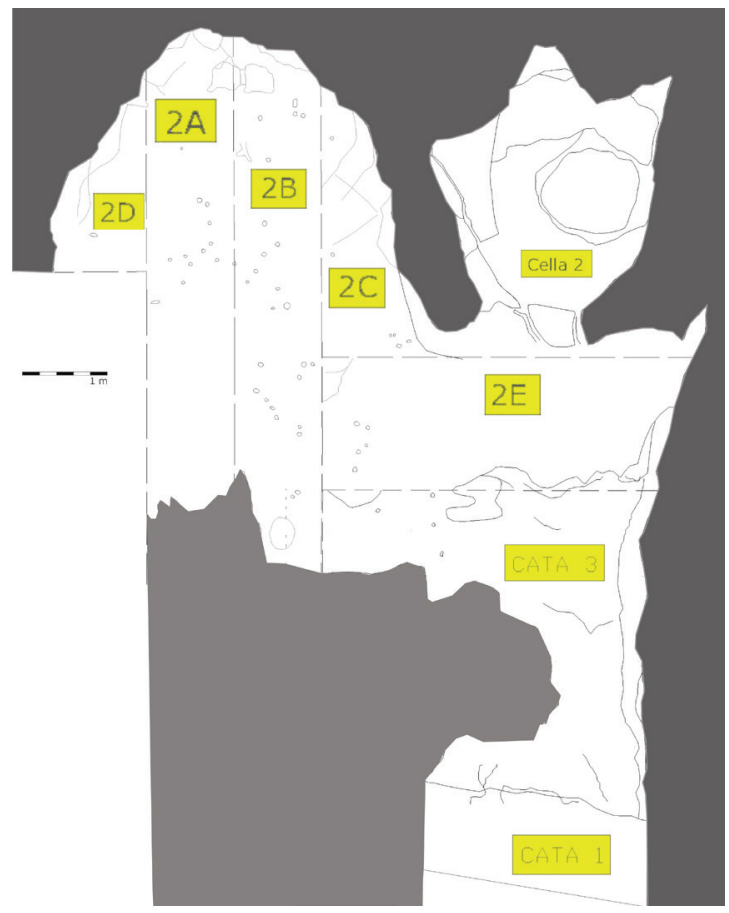

Figura 2. Localización de las catas llevadas a cabo en la Cova dels Jurats.

desplome de una parte importante de la techumbre se produjo con posterioridad al uso de la cueva durante la Antigüedad, sellando en más de dos terceras partes lo acumulado en el suelo, preservando el potencial arqueológico de toda esa amplia zona. Es por ello que las labores de excavación desarrolladas se han tenido que adaptar al espacio que quedó libre de esos desprendimientos, que corresponden con un pasillo lateral de poco más de un metro de ancho y el fondo de la cueva. Disponíamos, pues, de un espacio reducido en donde trabajar, problemática a la que debe añadirse la documentación de varias acciones de expolio que destruyeron parte de ese escaso potencial arqueológico no afectado por el desprendimiento del techo.

Desde el punto de vista metodológico se distinguieron tres catas arqueológicas (Fig. 2) (Orfila et al. 2015: 65):

Cata 1, sondeo realizado en 2010 (con una leve ampliación en 2011) en el pasillo de acceso, con el objetivo de calibrar el potencial arqueológico de la gruta. Permitió también determinar que la cueva fue utilizada con anterioridad a que se produjese el derrumbe del techo, pues éste sella gran parte de la estratigrafía. De $1 \mathrm{~m}$ de ancho (sentido Norte-Sur), por 1,70 en sentido Este-Oeste, y una potencia de unos $40 \mathrm{~cm}$, además de la secuencia estratigráfica, en la Cata 1 se documentaron dos agujeros de furtivo.

Cata 2, llevada a cabo en 2011 en el fondo de la cueva (comprendiendo el ábside central y la cella 2, así como el sector inmediatamente delante de ésta). Debido a la localización del corte y la forma de la cueva, la Cata 2 resulta bastante irregular, con unas dimensiones máximas de unos 6 por 6 metros. La excavación mostró, por una parte, que el fondo de la cavidad presentaba una potencia muy reducida, en algunos sectores apenas unos $10 \mathrm{~cm}$, aunque sí que se pudieron distinguir diferentes unidades estratigráficas, principalmente en la zona al abrigo de las grandes piedras que conforman el derrumbe (en el sector meridional de la cata). Por otra parte, la excavación de la cella 2 mostró que el sedimento se encontraba totalmente revuelto (consecuencia tal vez de la actuación de furtivos).

La excavación evidenció la existencia de una serie de marcas en la roca en el suelo del ábside central, huellas de los trabajos de rebaje y acondicionamiento de la zona. También se documentó algún tipo de rebaje en la pared del fondo, circunstancia que, como ya se ha mencionado, ha sido vinculada a la aparición de unos agujeros en el suelo y a la posible presencia de algún tipo de elemento o imagen de culto.

Cata 3 (2012), permitió unir las dos catas anteriores y completar la secuencia estratigráfica de la cueva. Con unas dimensiones máximas de 3 por 4 metros, la cata se adapta a la presencia del derrumbe de piedras en su lado occidental. La excavación mostró una potencia de unos $30 \mathrm{~cm}$, con una estratigrafía muy clara que repetía esencialmente la ya documentada en la Cata 1 (de la que hablaremos un poco más adelante). Se volvió a documentar la actuación de furtivos, en este caso a través de un agujero con forma cuadrada de 2 por $2 \mathrm{~m}$, que agotó secuencia llegando hasta la roca.

A pesar del derrumbe de la techumbre, y de las diversas actuaciones de furtivos detectadas, se ha constatado una interesante secuencia estratigráfica que permite afirmar que el uso que se le dio 


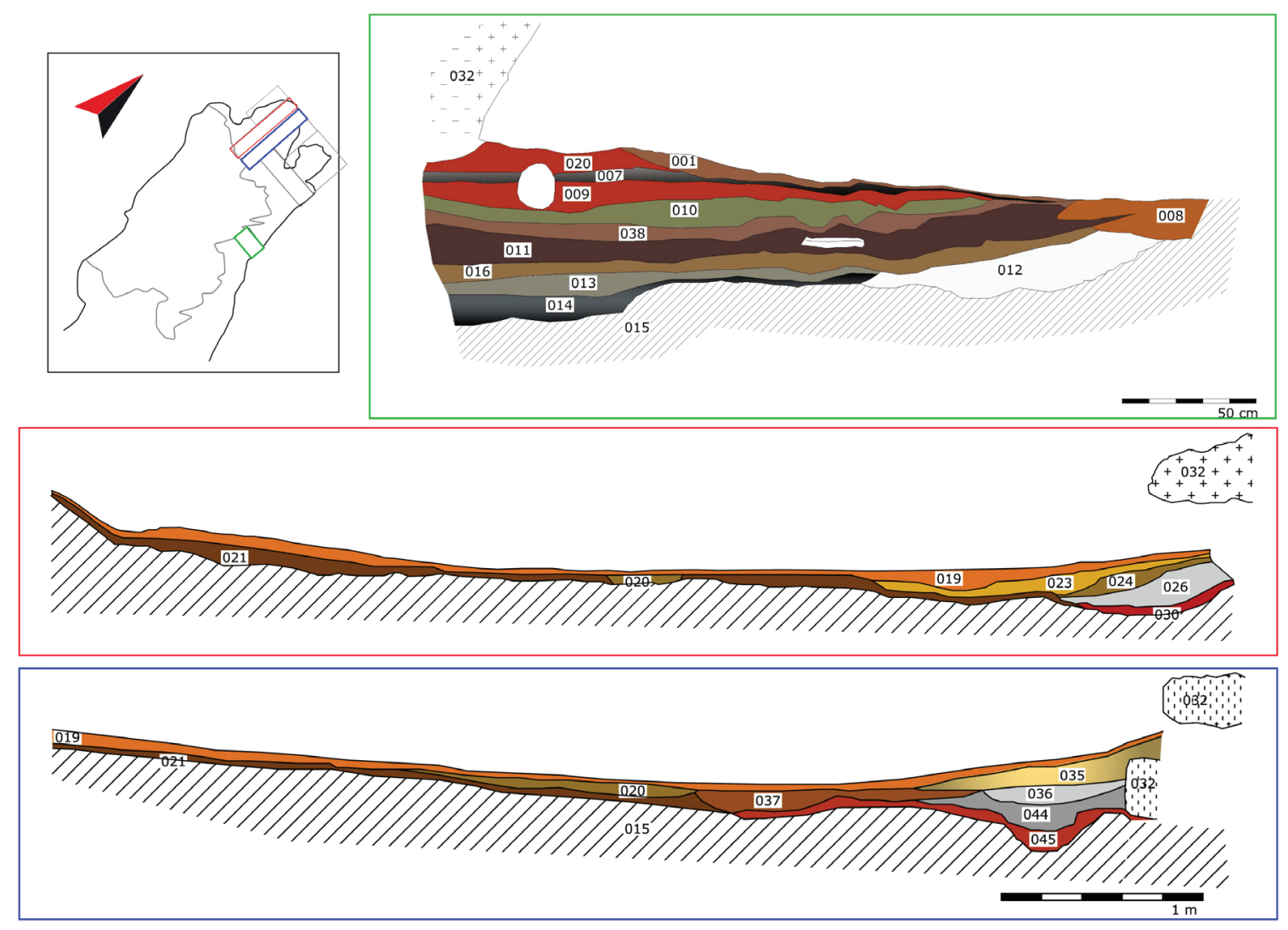

Figura 3. Secciones estratigráficas de las catas 1 y 3 .

a esta cueva en época antigua no tiene nada que ver con la del centenar de cuevas artificiales recortadas en los acantilados de esta ensenada, con funcionalidad funeraria en época Talayótica.

Como se ha explicado, son las Catas 1 y 3 las que han arrojado una mayor potencia, mostrando una estratigrafía bastante reiterativa (Fig. 3). Sobre la roca madre (UE15) se llevó a cabo una primera regularización del suelo, sobre él se debió desarrollar una actividad en la que la combustión estuvo presente, dada la cantidad de carbones recuperados en la UE14. Sobre ese nivel se aprecia la realización de otro piso, esta vez a base de piedras y arenisca, que forma un suelo de paso (UE13). A continuación se documenta un nivel de uso (UE16), sobre el que se ha realizado de nuevo una combustión (UE11) ${ }^{1}$, y sobre esta unidad, la UE38 una nueva nivelación del suelo a base de piedras y tierra blanquecina. Tiene un uso en la UE10, sobre la que se aprecia de nuevo un nivel de combustión, en este caso la UE09, para de nuevo nivelarse rehaciendo un piso (UE07)
(Orfila et al. 2010: 455-460; Orfila et al. 2013: 111; Orfila et al. 2015: 66).

Un elemento especialmente interesante en relación a la estratigrafía documentada en las Catas 1 y 3 , es la presencia de una escorrentía paralela a la pared de la cueva, que parece pudo recoger el agua procedente de la Cella 2. Dicha escorrentía apareció llena de materiales arqueológicos, tanto huesos como cerámica de diferentes cronologías, todo muy mezclado. Dando la sensación de que pudiera producirse periódicamente algún tipo de "limpieza" del suelo que la cueva, desechándose los restos en este sector.

\section{Registro cerámico de la Cova del Jurats}

La excavación llevada a cabo en la Cova dels Jurats ha supuesto la recuperación de una gran cantidad de material arqueológico, no sólo cerámico. Destaca especialmente la documentación de una ingente cantidad de restos faunísticos, muy espe- 


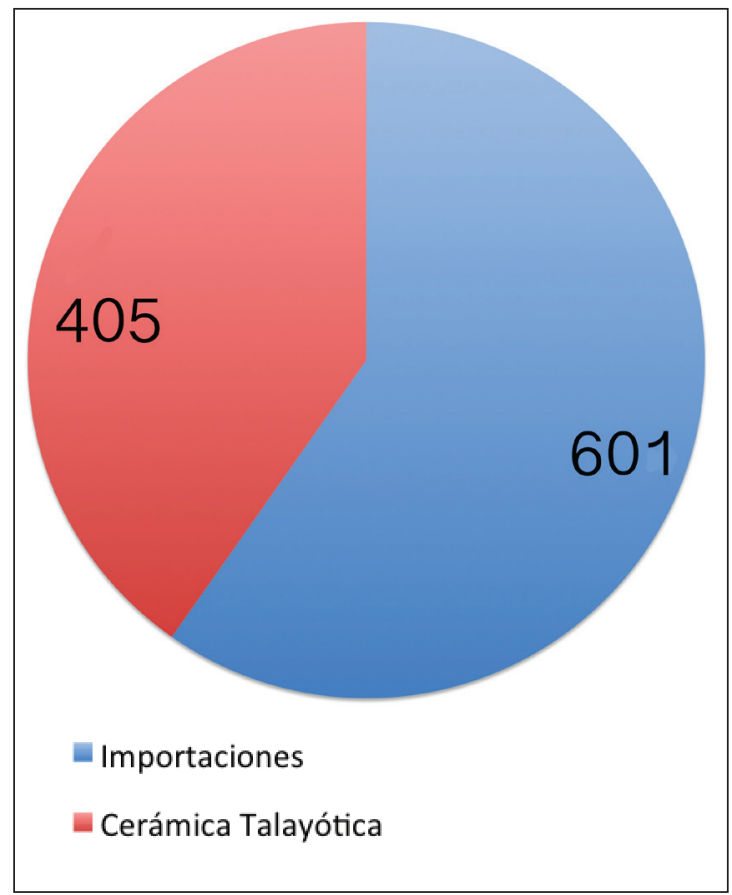

Figura 4. Proporción de materiales cerámicos locales (cerámica a mano de tradición talayótica) y de importaciones en el registro de la Cova de l’Esglesia (número de fragmentos).

cialmente fauna terrestre, en muchas ocasiones quemada, y con marcas sobre los huesos de acción de descuartizamiento ${ }^{2}$. Al igual que sucede con la cerámica, los restos animales aparecieron enormemente fragmentados.

En lo que respecta al registro cerámico, hay que llamar la atención sobre la existencia de dos grandes conjuntos fundamentales, por una parte las producciones locales tardías, propias del talayótico final, y por otra las importaciones, procedentes de diferentes puntos del Mediterráneo (Fig. 4).

Comenzaremos con el conjunto más homogéneo de los dos que hemos citado, el conformado por la cerámica de tradición talayótica (Figs. 5 y 6). Predominan aquí los cuencos o vasos de tamaño mediano o pequeño, tanto en forma de vasos cónicos de borde recto (tipo Ala, Rosselló 1984), cónicos de borde triangular (tipo A1b, Rosselló 1984) y concoides (tipo B5, Rosselló 1984). También se han documentado vasos ovoides de borde entrante (tipo B4, Rosselló 1984), y cónicos de labios rectos y boca exvasada (tipo A2, Rosselló 1984). Dentro del conjunto de bases,

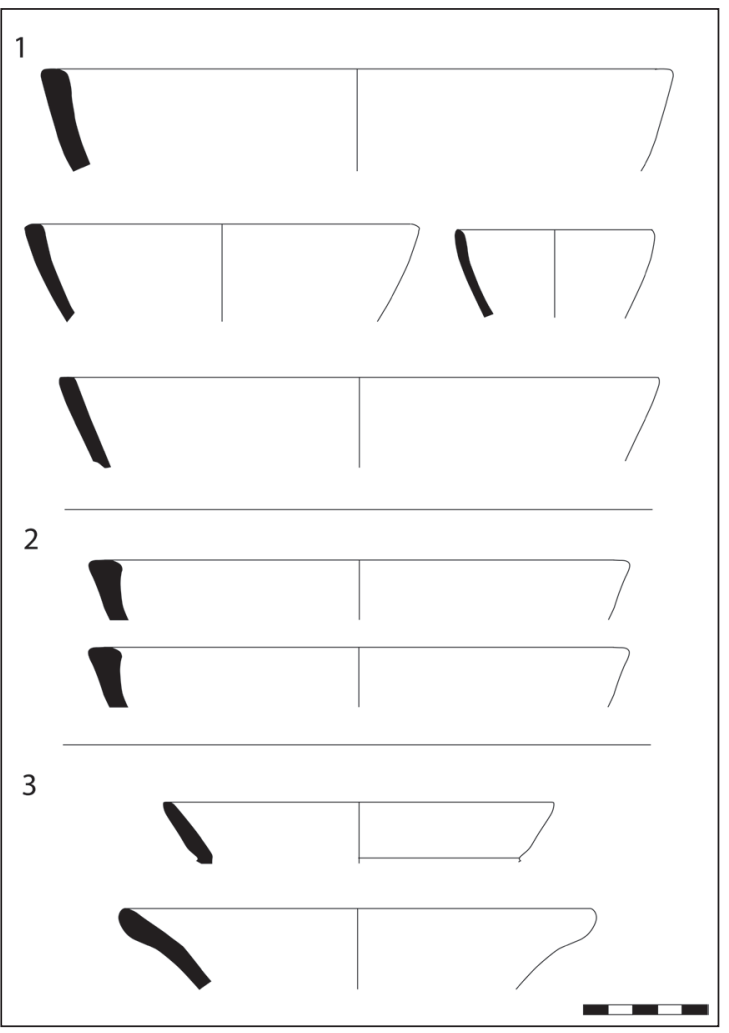

Figura 5. Cerámicas talayóticas: vasos cónicos. 1. vasos cónicos de borde recto; 2 . vasos cónicos de borde triangular; 3 . vasos cónicos de labio recto y boca exvasada.

se han podido distinguir dos grandes grupos, las bases planas, típicamente talayóticas, y aquellas de pie diferenciado. Estas últimas evidencian la existencia de producciones locales enormemente influidas por las formas propias de cerámicas de importación, esencialmente los barnices negros campanienses y sus imitaciones ibicencas. Estas cerámicas a mano, imitando formas a torno de procedencia Mediterránea, han sido fechadas entre los siglos IV y II a.C., estando especialmente generalizadas en el s. III a.C. (Plantalamor y Rita 1985: 376; Plantalamor y Rita 1986: 380).

Entre los materiales locales destacan también dos fragmentos de vasos de fondo alto o vasos con cartela (según Veny 1982), forma que imita los pebeteros helenísticos, de funcionalidad ritual, y que se fecha entre el siglo IV a.C y el s. I d.C. (Prados Torreira 1983; Sastre Moll 1985).

El otro gran grupo está formado, como se ha visto, por los materiales de importación. Dentro de este conjunto destacan cerámicas de procedencia ebusitana, barnices negros, megárica, gris 


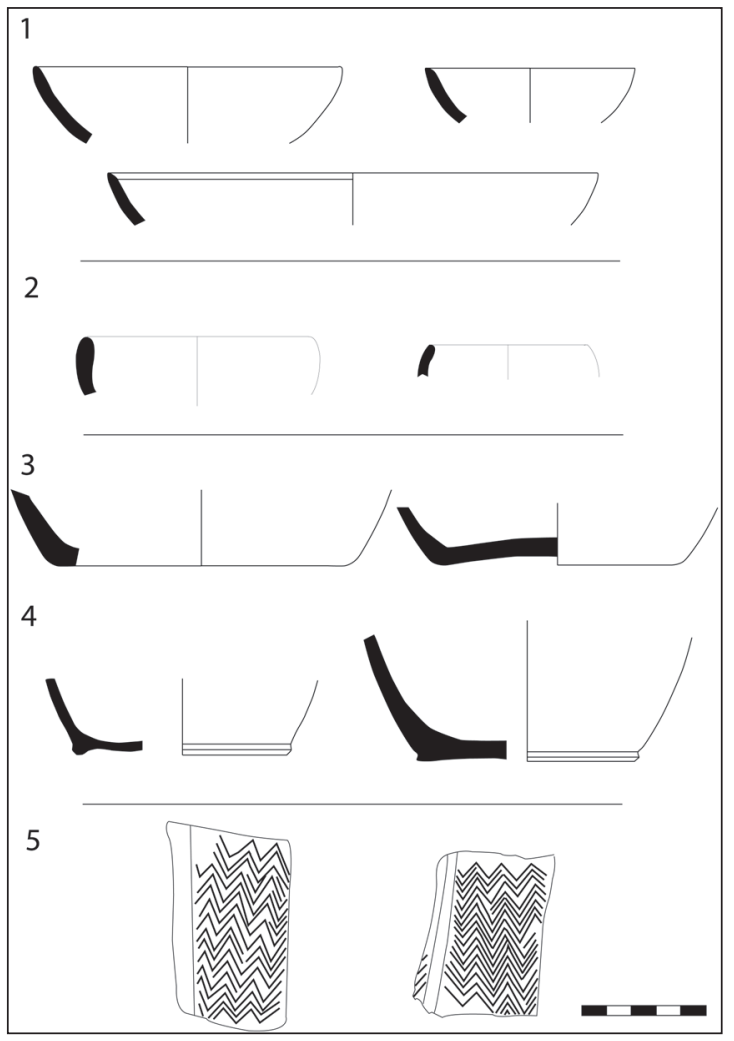

Figura 6. Cerámicas talayóticas: 1. vasos concoides; 2. vasos ovoides de borde entrante; 3 . bases planas; 4. bases con pie diferenciado; 5 . fragmentos de vasos de fondo alto.

ampuritana, común romana, cerámica de paredes finas, lucernas, sigillatas clásicas y norteafricanas, cerámica de cocina y ánforas ${ }^{3}$. Todo ello enormemente fragmentado, lo que ha dificultado enormemente el análisis de las formas (Figs. 7 y 8).

Cerámica ebusitana:

Entre los materiales de procedencia púnicoebusitana, destaca un plato de pescado de labio colgante, tipo que se fabricó en Ibiza entre los siglos IV y II a.C. (Guerrero 1999: 17). Por su parte, entre las formas más frecuentes reconocidas se encuentran las jarras, entre ellas hemos podido reconocer el tipo $\mathrm{Eb}$ 21 (Ramon 2012: fig. 2.7), y posiblemente el Eb 77 (Ramon 2012, fig. 2.6), fechados en los siglos III-II a.C., o los pequeños cuencos de borde más o menos entrante del tipo I.2.a de fábrica ebusitana definidos por Guerrero Ayuso, fechados entre principios s. III y la segunda mitad del s. II a.C. (Guerrero 1999: 11).

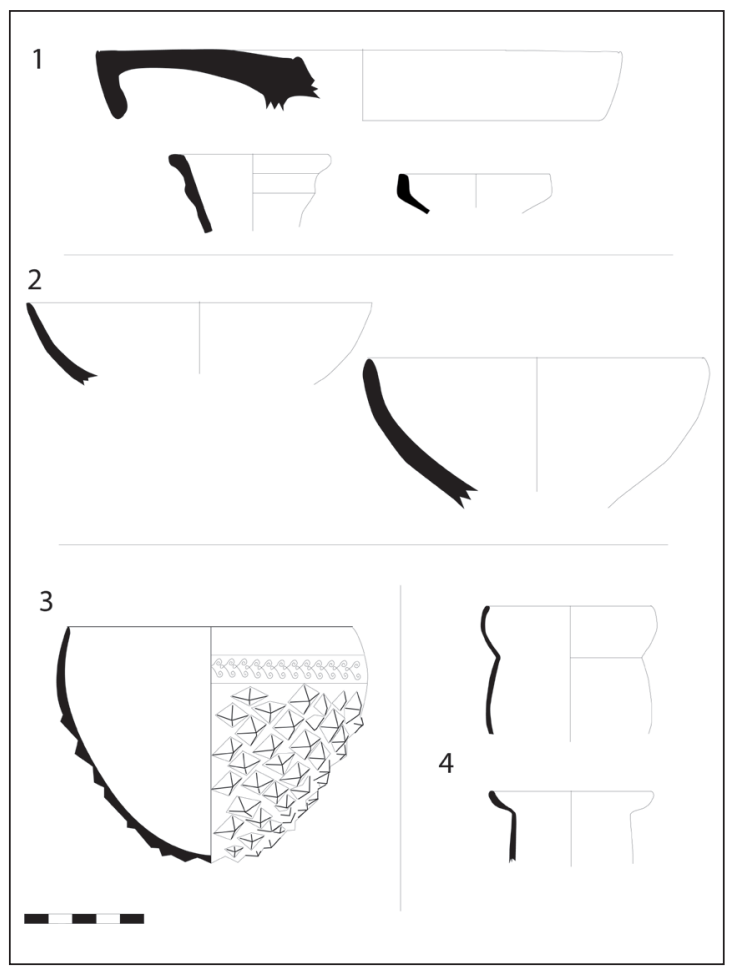

Figura 7. Cerámicas de importación: 1. ebusitana; 2. Barnices negros; 3. megárica; 4. paredes finas.

Barnices Negros:

Se trata esencialmente de boles. Se han podido reconocer las formas Morel 2862 (Orfila et al. 2010), fechable entre finales del siglo III y finales del siglo II a.C., y posiblemente Morel 2981, adscribible a los primeros decenios del s. III a.C.

Cerámica megárica:

Los boles helenísticos con relieve a molde a los que pertenecen los fragmentos hallados en la Cova dels Jurats fueron producidos seguramente en talleres ubicados en Jonia. Habiendo identificado con seguridad solamente uno de estos talleres, el del Monograma (Sánchez y Orfila 2015).

Con respecto a las fechas exactas en las que estuvo en funcionamiento este taller, los estudios tradicionales han defendido una cronología que va desde mediados del siglo II a mediados del siglo I a.C. (Laumonier 1977; Cabrera 2004), aunque con un floruit que habría que situar en los últimos años del siglo II a.C. (Cabrera 1979: 103-104; Cabrera 2004: $65)$, o de manera más amplia en la segunda mitad del siglo (Schmid 2006: 49). Según Schmid, los boles tipo piña, tipología a la 


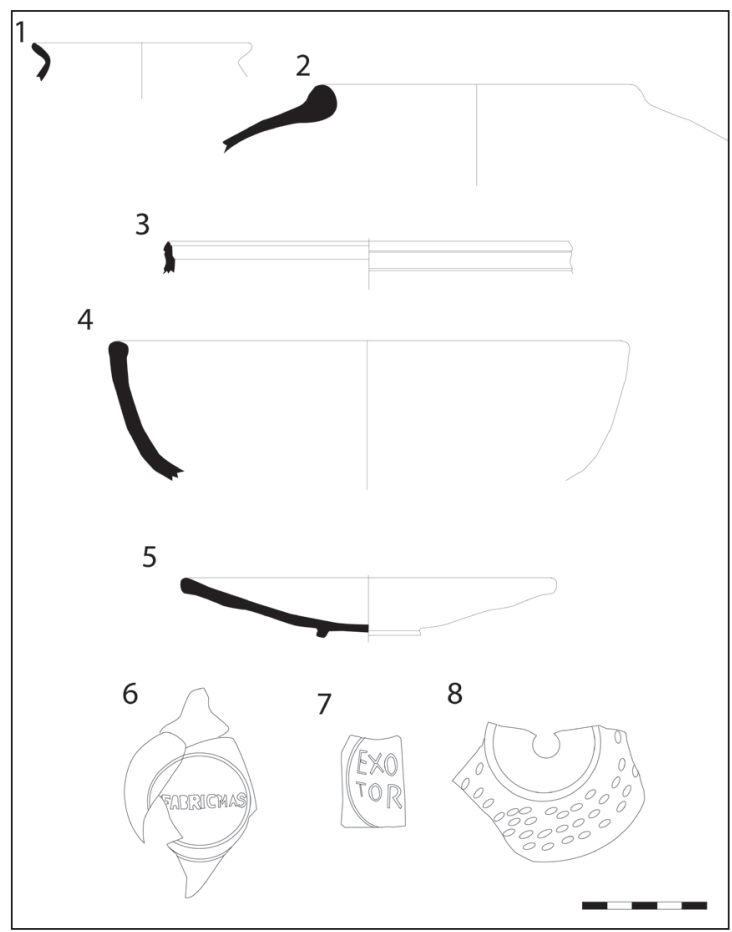

Figura 8. Cerámicas de importación: 1-2 comunes; 3. Terra Sigillata Itálica; 4. Terra Sigillata Africana; 5 cocina norteafricana; 6-7-8 lucernas.

que pertenece la pieza más completa entre las documentadas en la excavación, y aquellos con decoraciones de hojas imbricadas, se encontrarían entre las producciones más antiguas de este taller, y por lo tanto entre aquellas que habría que fechar en el segundo o tercer cuarto de ese siglo II a.C. (Schmid 2006: 49).

Cerámica Gris de la Costa Catalana:

Los fragmentos cerámicos catalogados en este grupo no han aportado información suficiente para la identificación de formas. En general esta cerámica se produce entre la segunda mitad del s. IV y el s. III a.C. (Bonet y Mata 2008: 151-153)

Cerámica de paredes finas:

De nuevo, el reducido tamaño de los fragmentos recuperados dificulta la clasificación de los materiales. Se trata, en la mayoría de los casos identificados, de cubiletes y cuencos, procedentes seguramente de la vecina Ibiza. Así, se han podido distinguir cubiletes de la forma 3 y de alguna variante de la forma 2 (Lopez Mullor 2008), además de algunos fragmentos probablemente atribuibles a ejemplares béticos, comunes en las Baleares a partir de finales del principado de Claudio (Lopez Mullor 2008: 344).

Común romana:

A pesar del número de fragmentos de cerámica común recuperados, muy pocos proporcionaron forma. Entre ellas destacan algunas formas cerradas tipo olla u orzas y cuencos, así como tapaderas.

Lucernas:

El registro muestra un importante número de fragmentos de lucernas, seguramente vinculado a la necesidad de luz en el interior de la cueva. Sin embargo, el reducido tamaño de los fragmentos hace difícil su estudio. Aún así destaca el hallazgo de una lucerna de disco del tipo Deneauve 7a, producida por el taller de L. Fabricius Masculus, según se desprende del sello de la base: FABRIC MAS. El disco superior de la lucerna presenta la imagen de un león.

Esta pieza, producida en Italia, debe fecharse entre finales del s. I y mediados del s. II d.C. (Balil 1968: 171; Bailey 1980: 95; Casas y Soler 2006: 53; Abascal y Cebrian 2008: 187-192).

Se recuperó también otro fragmento de lucerna con sello, en el que se podía leer: EX O[--] TOR[--].

Sigillatas Clásicas:

Durante las tres campañas de excavación en la Cova de l'Esglesia se recuperaron tan solo seis fragmentos, y únicamente uno de ellos permitió reconocer la forma. Se trata de una Godineau 28 o Conspectus 19.2, una forma muy típica de la sigillata Itálica, fechable en el primer tercio del siglo I d.C.

Sigillatas Africanas:

Muy similar es el caso de las sigillatas africanas, con sólo 4 fragmentos, entre ellos una Lamboglia 3a/Hayes $14 \mathrm{~A}$, atestiguada en Ostia durante los siglos II-III d.C (Atlante 1981: 32).

Cerámica de cocina:

Se han recuperado fragmentos de cerámica de cocina de procedencia itálica así como norteafricana, pero, de nuevo, son escasos los que han permitido la clasificación formal de este material. Entre ellos, varios fragmentos de platos de cerámica de cocina norteafricana (Orfila et al. 2010), concretamente tapaderas tipo Ostia II figura 302 (Atlante 1981: 212), fechados entre finales del siglo I a.C. e inicio del I d.C., pudiendo llegar a 
la segunda mitad del siglo II d.C., o platos Ostia I figura 18 (Atlante 1981: 212), que pueden llegar hasta siglo III.

Ánforas:

Al igual que sucede con el resto de los materiales, las ánforas aparecen enormemente fragmentadas, lo que ha impedido identificar formas. Aún así, se ha podido distinguir la presencia de ánforas púnico-ebusitanas, itálicas y béticas, según se aprecia por el tipo de pastas de los fragmentos de paredes que de este tipo de envases se han recuperado.

\section{Cronología y usos de la Cova dels Jurats. ¿Un santuario rupestre talayótico?}

En base a los materiales recuperados durante la excavación arqueológica de la Cova dels Jurats y al estudio de las inscripciones documentadas a la entrada de la misma, se pueden distinguir claramente dos fases en el uso del interior de la cueva y su entorno durante la Antigüedad, así como una fase posterior de frecuentación esporádica:

Fase 1. Correspondiente al periodo Talayótico Final (s. III-I a.C.), momento durante el que probablemente funcionó como santuario, a diferencia del uso funerario dado al resto de las cuevas de Calescoves.

Fase 2. Vinculada al santuario romano y sus inscripciones (s. II-III d.C.). Los materiales del siglo I d.C. documentados se podrían asociar también a esta segunda fase de uso cultual, si la superposición de inscripciones que se ha podido documentar en algunos sectores del panel epigráfico (Orfila et al. 2013: 114) supuso la desaparición de epígrafes más antiguos a los conservados.

Fase 3. Frecuentación post-clásica. Esta se identifica a través del hallazgo de una moneda tardía, cuyo estado de deterioro sólo permite indicar que se trata de un aes posiblemente del siglo IV dC., además de la presencia esporádica en los niveles superficiales de cerámica medieval y moderna.

A la primera fase le corresponden un importante número de materiales de producción local, así como vasos de importación púnico-ebusitanos, barnices negros y cerámicas megáricas, paredes finas y cerámicas comunes. Todos ellos enorme- mente fragmentados y mezclados con fauna, en ocasiones quemada, formando una estratigrafía bastante clara y repetitiva, que, como ya hemos visto, parece evidenciar el uso del fuego.

Entre las formas que han podido ser identificadas, predominan los vasos o cuencos, ya sean de importación o en producciones locales, en muchos casos imitando formas de la cerámica campaniense; aunque destaca también la aparición de jarritas de procedencia púnico-ebusitana. Formas, en cualquier caso, especialmente vinculadas al consumo de líquidos en general, o de vino en particular, como parece suceder con los boles helenísticos procedentes de Jonia.

Este tipo de registro muestra una gran similitud con el hallado en los santuarios típicos de la cultura Talayótica, los Recintos de Taula, excavados en la isla de Menorca, donde se han identificado hogueras con fragmentos de cerámica y huesos en su interior (Gornés 2008). Así, en Torralba d'en Salord, entre los materiales asociados a la hoguera, se recuperaron cerámicas talayóticas, ibicencas, ibéricas, grises ampuritanas y barnices negros, y ánforas muy fragmentadas ${ }^{4}$ (Fernández-Miranda y Waldren 1995; Fernández-Miranda 2009: 42-43 y 52-55). En el monumento 2 de So Na Caçana se documentaron cerámicas de procedencia púnica, itálica, ibérica y talayótica, vinculadas también a la hoguera (Plantalamor 1991b: 381; Gornés 2008). El santuario de Binissafullet presenta un registro comparable, con hoguera, restos de fauna, y cerámicas talayóticas, incluyendo imitaciones de cuencos de barniz negro, y púnico-ebusitanas (Gual y Plantalamor 1995). Evidencias todas ellas que han sido puestas en relación con "la existencia de un fuego de combustión continua en el que se practicaban ofrendas en forma de carne, vasos cerámicos y probablemente líquidos" (Gornes 2008: 490).

Ante la similitud de los registros arqueológicos de estos santuarios con el documentado en el interior de la Cova dels Jurats de Calescoves, consideramos muy probable que aquí se estuviese realizando una actividad muy similar, algún tipo de ritual, en el que la comensalidad tuviese un papel primordial. Con lo que podríamos tal vez encontrarnos ante el primer santuario rupestre conocido asociado a la cultura talayótica, tanto Mallorquina como Menorquina.

Pero al mismo tiempo, las características del santuario de Calescoves recuerdan de manera muy particular a los santuarios fenicio-púnicos del Mediterraneo occidental. En este sentido, un elemento a destacar por ejemplo es la presencia 
de agua, circunstancia recurrente en las cuevassantuario en la Antigüedad (Gómez y Vidal 2000), especialmente en el caso de los santuarios púnicos, cuya existencia en muchos casos "se ha iniciado con el culto a las aguas" (Aubet 1988: 242). Su presencia ha podido ser observada por ejemplo en los santuarios de Es Cuieram (Ibiza) (Aubet 1969 y 1982; Gómez y Vidal 2000: 111-113) y Ras IlWardija (Malta) (Ciasca 1970; Gómez y Vidal 2000: 108-109). En el caso de la Cova dels Jurats, el líquido elemento era recolectado en la Cella 2 y canalizado en la escorrentia lateral ya descrita.

También la ubicación de la cueva parece vincularla con otros santuarios fenicio-púnicos, caracterizados por tratarse de cuevas naturales, situadas en acantilados sobre el mar o cercanos a este, en lugares aislados pero ubicados en puntos estratégicos para la navegación (Gómez y Vidal 2000: 122), como sucede por ejemplo en Grotta Regina (Sicilia) (Bisi 1969; Gómez y Vidal 2000: 109-111) o Gorham's Cave (Gibraltar) (Gómez y Vidal 2000: 113-114; Gutiérrez et al. 2014). Así, la Cova dels Jurats se encuentra algo elevada dominando la ensenada de Calescoves, un punto fundamental en la navegación por el archipiélago debido a la presencia de agua dulce en abundancia, pero además esencial para el contacto de los comerciantes con las poblaciones afincadas en el interior de la isla.

Esta ubicación tan específica de los santuarios púnicos en puntos cercanos al mar parece vincularse de forma directa con la finalidad de los mismos, lugares en los que los marineros realizarían rituales destinados a ganarse el favor de sus divinidades para garantizarse una buena travesía, o agradecerles el haber llegado sanos y salvos hasta ese punto (Gómez y Vidal 2000: 122; Medas 2008: 155; Christian 2013: 182). En este sentido, cabe llamar la atención sobre el hecho de que el Estadiasmo o Periplo del Mar Grande, uno de los periplos náuticos más antiguos conocido, incluye templos y santuarios costeros entre los elementos útiles reseñados en estos documentos prácticos para navegantes (Medas 2008).

En estos santuarios púnicos, como los de Ras Il-Wardija, Grotta Regina, Es Cuieram, o Gorham's Cave, se llevaron a cabo ritos que debieron incluir libaciones, ofrendas de alimentos y tal vez algún ritual de comensalidad, como demuestra la presencia de jarras, platos, cuencos, ánforas, en incluso restos animales y hogueras. Una circunstancia que de nuevo se repite en el santuario de Calescoves, aunque en este caso con un importante componente indígena evidenciado en la fuerte presencia de cerámicas talayóticas. Indicando que las poblaciones locales pudieron también estar utilizando este espacio realizando tal vez rituales similares, como demostraría el hecho de que las producciones locales identificadas repitan las formas documentadas en los otros santuarios, especialmente cuencos.

A esto debemos añadir además otra circunstancia, pues, como ya hemos visto, este registro se repite también en otros centros cultuales menorquines, concretamente en el Talayótico Final de los recintos de Taula (Gornés 2008). Lo que lleva a plantear una cuestión sumamente interesante, la de la "colonización fenicio-púnica" de Menorca. Donde a pesar de no existir colonias senso stricto, sí que se produjeron importantes contactos entre indígenas y púnicos, como queda patente en la destacable presencia de productos ibicencos en los poblados talayóticos (Guerrero et al. 2002: 247). En este sentido, en la vecina Mallorca se ha propuesto que dichos contactos producirían ciertas influencias en la esfera ideológica local, donde los santuarios indígenas tardíos estarían vinculados a "las necesidades de los nuevos cultos introducidos por los colonos púnicos que, adaptados y reinterpretados sincréticamente por la población indígena, son aceptados y entran en uso, al menos hacia los siglos V-IV a.C." (Guerrero Ayuso 1986: 371).

Los cambios fruto de los contactos coloniales parece que afectaron a los aspectos religiosos y rituales de la sociedad talayótica, observándose un particular proceso de aculturación o hibridación (Van Dommelen 2011), en la que parte de los rituales típicamente púnicos (libaciones, ofrendas de alimentos y comensalidad, evidenciados a partir de la presencia de jarras, platos, cuencos, huesos de animales y hogueras) se trasladan a los recintos de culto indígena, las Taulas. Un proceso de hibridación que en Calescoves queda evidenciado por ejemplo a través de la coexistencia en los diferentes niveles de uso de materiales indígenas e importados, y de la utilización de nuevos tipos cerámicos influidos por formas foráneas. Dos circunstancias que se han utilizado para definir contextos de hibridación en la Mallorca postalayótica (Calvo et al. 2014: 128).

De este modo, la ensenada de Calescoves, enclave estratégico en los contactos comerciales de las islas, se convierte en un punto vital en el contacto entre colonizadores e indígenas, contacto que queda materializado en esta Fase 1 del santuario. Y que a su vez debió ser clave para el surgimiento de "estructuras culturales híbridas" 
(García Cardiel 2014: 84) como los rituales desarrollados en los recintos de Taulas en este mismo periodo. Surgen así prácticas diferentes de las propias de la tradición indígena, pero que sin embargo no coinciden exactamente con aquellas privativas de las poblaciones coloniales, si no que se ha generado "un nuevo contexto propio, único, originado en el ámbito de contacto entre ambas comunidades" (Calvo et al. 2014: 128).

Totalmente diferentes parecen las circunstancias de la Fase 2, asociada a la realización de las inscripciones estudiadas en el exterior de la cueva. Aunque en este momento, el conjunto sigue manteniendo su función religiosa, el ritual y el contexto han cambiado por completo. Se han podido analizar los restos de 29 inscripciones, fechadas entre el 125 y el 230 dC., y vinculadas a la celebración de los Parilia y el nacimiento de Roma (Orfila et al. 2010: 463-467; 2013: 115-117; 2015: 78-88).

No se trata ya, por tanto, de un ritual indígena o púnico, realizado en el interior de la cueva; sino un ritual romano, y como tal, desarrollado en su parte exterior. Buena muestra de que el interior de la gruta parece que ya no es utilizado en esta segunda fase, es la escasez de material directamente adscrito a este momento. Las sigillatas clásicas y africanas, las cerámicas de cocina norteafricanas, y las lucernas alto imperiales, materiales que abarcan esencialmente los siglos II y III d.C., están representadas por muy pocos fragmentos, recuperados esencialmente en las unidades superficiales, la escorrentía y los agujeros de furtivo. Circunstancia que podría indicar que tal vez durante la Fase 2, el interior de la cueva solamente fue frecuentado esporádicamente.

¿Estaría vinculado el abandono del ritual interior sólo al cambio de contexto cultural, sobre todo a partir de la municipalización de Mago e Iamo en época Flavia? ¿O puede estar vinculado al derrumbamiento de parte del techo de la cueva? Sólo la excavación bajo el derrumbe podría darnos una respuesta.

\section{Notas}

1. En la analítica efectuada por la Dra. E. Grau de la Universitat de València, los resultados preliminares en cuanto a los restos de maderas carbonizadas identificadas en una muestra de 100 fragmentos pertenecientes a esta UE11, han sido los siguientes: Olea europea (60\%), Pinus halepensis (15\%), Quercus ilex-coccifera (20\%) y Rhamnus/Phillyrea (5\%) (Orfila et al. 2015: 66).

2. Los restos faunísticos se encuentran en la actualidad pendientes de estudio y por el momento no se pueden aportar conclusiones de tipo tafonómico.

3. A estos materiales hay que añadir algunos fragmentos de cerámicas medievales y modernas, evidencia de la frecuentación de la Cova de l'Esglesia hasta fechas recientes.

4. En otros puntos de recinto se recuperaron además paredes finas republicanas y lucernas romanas (Fernández-Miranda y Waldren 1995).

\section{Bibliografía}

Abascal Palazón, J.M.; Cebrián Fernández, R. (2008): Marcas de alfarero en lucernas romanas descubiertas en Segóbriga. Verdolay, 11: 179-224.

AtLante (1981): Atlante delle forme ceramiche I. Ceramica fine romana del bacino Mediterraneo (Medio e Tardo Impero).

Aubet, M.E. (1969): La Cueva d'es Cuiram. Ibiza. Publicaciones eventuales, Universidad de Barcelona.

Aubet, M.E. (1982): El Santuario de Es Cuiram. Trabajos del Museo Arqueológico de Ibiza 8, Ibiza.

Aubet, M.E. (1988): España. Los fenicios (S. Moscati, dir.), Barcelona: 226-242.

BaILey, D. M. (1980): A Catalogue of the Lamps in the British Museum, vol. II. Roman Lamps made in Italy. London.

BALIL, A. (1968): Marcas de ceramista en lucernas romanas halladas en España. Archivo Español de Arqueología, 41: 158-178.

Belén, M.; Fernández-Miranda, M. (1979): El fondeadero de Cales Coves (Menorca, Islas Baleares). Excavaciones Arqueológicas en España 101, Madrid. 
BIsI, A.M. (1969): Lo scavo del 1969. Grotta Regina I. Rapporto preliminare della Missione congiunta con la Soprintendenza alle Antichità della Sicilia Occidentale (A.M. Bisi, M.G. Guzzo Amadasi, V. Tusa (eds.). Roma, Consiglio Nazionales delle Ricerche. Centro di studio per la civiltà fenicia e punica.

Bonet, H; Mata, C. (2008): Las cerámicas ibéricas. Estado de la cuestión. Cerámicas hispanorromanas. Un estado de la cuestión (D. Bernal Casasola, A. Ribera i Lacomba. eds.). Universidad de Cádiz, Cádiz: 147-169.

CABrera Bonet, P. (1979): La cerámica helenística de relieves de Cartagena. Cuadernos de Prehistoria y Arqueología, 5-6: 81-104.

CABrera, P. (2004): La cerámica helenística de relieves de la Alcudia. El yacimiento de La Alcudia (Elche, Alicante): pasado y presente de un enclave ibérico (T. Tortosa, ed.), Anejos del Archivo Español de Arqueología: 55-69.

Calvo Trías, M.; García Roselló, J.; Albero Santacreu, D.; JaValoyas Molina, D. (2014): Prácticas híbridas y espacios intermedios: los contextos cerámicos de la Bahía de Santa Ponça (Clavià, Mallorca) (s. II a.C.). In amicitia. Miscelània d'estudis en homenatge a Jordi H. Fernández (C. Ferrando, B. Costa, eds.). Museo Arqueológico de Ibiza y Formentera, Ibiza: 113-132.

Casas i Genover, J. y Soler i Fusté, V. (2006): Llànties romanes d'Empuries. Materials augustals i altoimperials. Monografies emporitanes 13, Girona.

Christian, M. A. (2013): Phoenician Maritime Religion: Sailors, Goddess Worship, and the Grotta Regina. Die Welt des Orients, 43: 179-205.

Ciasca, A. (1970): Ricerche puniche a Malta. Ricerche puniche nel Mediterraneo Centrale, Roma: 91-110.

Fernández-Miranda, M. (1979): Torralba d'en Salort. XV Congreso Nacional de Arqueología, Zaragoza: 559-572.

Fernández-Miranda, M. (2009): El poblado de Torralba d'en Salort (Alaior-Menorca). Consell Insular de Menorca, Mahón.

Fernández-Miranda, M.; BeléN, M. (1977): Arqueología submarina en Menorca. Fundación Juan March, Madrid.

Fernández-Miranda, M.; Rodero, A. (1991): Arqueología subacuática en Baleares. Jornadas de arqueología subacuática en Asturias, Universidad de Oviedo: 133-145.

FERNÁNDEZ-Miranda, M.; WaLdREn, W. (1995): Función y significado de las taulas: el caso de Torralba d'en Salord. Ritual, Rites and Religion in Prehistory. IIIrd DEya International Conference of Prehistory vol. I. BAR International Series 611: 122-129.

GARCÍA CARDIEL, J. (2014): ¿Rasgos púnicos en los santuarios ibéricos? Religión e identidad en la Contestania central. Saguntum, 46: 79-91.

GARCía RiAZA, E.; SÁNCHEz León, M.L. (2000): Roma y la municipalización de las Baleares. Universitat de les Illes Balears, Palma.

Gómez Bellard, C. (2002): Ebusus. Valencia y las primeras ciudades romanas de Hispania (J.L. Jiménez, A. Ribera, coords.), Valencia: 103-112.

Gómez Bellard, C.; Costa, B.; Gómez Bellard, F.; Grau, E.; Gurrea, R.; Martínez Valle, R. (1990): La colonización fenicia de la isla de Ibiza. Excavaciones Arqueológicas en España 157, Madrid.

Gómez Bellard, C.; VidAl GonzÁlez, P. (2000): Las cuevas-santuario fenicio-púnicas y la navegación en el Mediterráneo. Santuarios fenicio-púnicos en Iberia y su influencia en los cultos indígenas (J.H. Fernández Gómez, B. Costa Ribas, coords.), Treballs del Museu Arqueologic d'Eivissa e Formentera, 46: 103-146.

GornÉs, S. (1997): Arqueología de la muerte y cambio social. Análisis e interpretación de la necrópolis de Cales Coves, Menorca. Complutum, 7: 91-103.

GoRnÉs, S. (2000): Ipogei del Talaiotico finale: analisi e interpretazionedella necrópolis di Cales Coves, Minorca. L'ipogeismo nel Mediterráneo: sviluppo, quadri culturali, Vol. II. Università degli Studi di Sassari, 1994, Sassari-Oristano: 553-571.

GoRNÉS, S. (2008): Nuevas aportaciones a los contextos arqueológicos y a la cronología de los santuarios de taula de Menorca. Saturnia Tellus. Definizioni dello spazio consacrato in ambiente etrusco, italica, fenicio-punico, iberico e celtico (X. Dupré Raventós, S. Ribichini, S. Verger, coord.), Roma: 489-506. 
GornÉs, S.; GuAL, J. (2000): El hipogeo XXI de la necrópolis de Cales Coves, Minorca. L'ipogeismo nel Mediterráneo: sviluppo, quadri culturali, Vol. II Università degli Studi di Sassari, 1994, Sassari-Oristano: 573-590.

Gual, J.; Plantalamor, L. (1995): La taula de Binissafullet. Ritual, Rites and Religion in Prehistory. IIIrd DEya International Conference of Prehistory vol. I. BAR I.S. 611: 200-212.

Guerrero, V.M. (1999): La Cerámica Protohistórica a Torno de Mallorca (s. VI-I a.C.). BAR International series 770, Oxford.

Guerrero Ayuso, V.M. (1986): El impacto de la colonización púnica en la cultura talayótica de Mallorca. Los fenicios en la Península Ibérica. Volumen II. Epigrafía y Lengua. Glíptica y Numismática. Expansión e Interacción Cultural. Apéndice: el elemento púnico en la cultura talayótica (G. Olmo Lete, M.A. Aubet, ed.), Barcelona: 339-375.

Guerrero Ayuso, V.M. (1999): La Cerámica Protohistórica a Torno de Mallorca (s. VI-I a.C.). BAR International series 770 , Oxford.

Guerrero Ayuso, V.M.; Calvo Trias, M.; Salvì Simonet B. (2002): La cultura talayótica una sociedad de la edad del hierro en la periferia de la colonización fenicia. Complutum, 13: 221-258.

Gutiérrez López, J.Ma; Reinoso Del Río, Ma C.; Sáez Romero, A.M.; Giles Pacheco, F.; Finlayson, J.C.; ZAMORA LóPEZ, J.A. (2014): El santuario de la Cueva de Gorham (Gibraltar). Estado de la cuestión (con la presentación de un nuevo grafito fenicio). Phéniciens d'Orient et d'Occident. Mélanges Josette Elayi. CIPOA vol. II (A. Lemaire, ed.), Paris: 619-629.

LAMOUNier, A. (1977): La céramique hellénistique à reliefs. I Les ateliers “ioniens”. École Francaise d'Athenes et Rome, Paris.

López Mullor, A. (2008): Las cerámicas de paredes finas en la fachada mediterránea de la Península Ibérica y las Islas Baleares., Cerámicas hispanorromanas. Un estado de la cuestión (D. Bernal Casasola, A. Ribera i Lacomba, eds). Universidad de Cádiz, Cádiz: 343-383.

MAYer, M. (2015): Santuario en época romana de la Cova dels Jurats o del Esglesia: estudio epigráfico de los paneles en el exterior de la gruta. Los santuarios de Cales Coves (Alaior, Menorca) (M. Orfila; G. Baratta; M. Mayer; E. Sánchez; M. Gutiéttez; P. Marín). Ayuntamiento de Alaior: 77-88.

Obrador, A. (2015): Nota geológica. Los santuarios de Cales Coves (Alaior, Menorca) (M. Orfila; G. Baratta; M. Mayer; E. Sánchez; M. Gutiéttez; P. Marín). Ayuntamiento de Alaior: 101-103.

Medas, S. (2008): Lo Stadiasmo o Periplo del Mare Grande e la navigazione antica, Gerión Anejos XII.

Orfila Pons, M. (1995): Arqueología Romana. Enciclopedia de Menorca, Tom Vuitè, Menorca: 195-264.

Orfila Pons, M.; MaYer, M.; Baratta, G. (2010): Los santuarios de Calescoves (Alaior, Menorca): Coberxo Blanc y Cova dels Jurats o de l'Esglesia. Informe preliminar. Cuadernos de Prehistoria y Arqueología de la universidad de Granada, 20: 439-477.

Orfila Pons, M.; Baratta, G.; Mayer, M. (2013): El Santuario de Calescoves (Alaior, Menorca: la Cova dels Jurats o Església. V Jornades d'Arqueologia de les Illes Balears (T. Riera, J. Cardell, coord.), Palma de Mallorca: 109-117.

Orfila, M.; Baratta, G.; MaYer, M.; SÁnchez, E.; GutiétTez, M.; Marín, P. (2015): Los santuarios de Cales Coves (Alaior, Menorca), Ayuntamiento de Alaior.

PÉrez Ballester, J. (2012): Sobre cerámicas Helenísticas en Iberia/Hispania. Significado y funcionalidad. Archivo español de Arqueología, 85: 65-78.

Plantalamor, L. (1991a): Los asentamientos costeros de la isla de Menorca. Atti del II Congreso Internazionale di Studi Fenici i Punici vol. Terzo. Roma: 1151-1160.

Plantalamor, L. (1991b): L'arquitectura prehistòrica i protohistòrica de Menorca i el seu marc cultural. Treballs del Museu de Menorca 12.

Plantalamor, L. y Rita, C. (1985): Influencia griega en la cerámica talayótica de Menorca. La vida quotidiana dins la perpectiva històrica. III Jornades d'estudis històrics locals. Institut d'Estudis Baleàrics, Palma de Mallorca: 345-353.

Plantalamor, L.; Rita, C. (1986): Influencia colonial en la cerámica indígena del talayótico final en Menorca. Los fenicios en la Península Ibérica. Volumen II. Epigrafía y Lengua. Glíptica y Numismática. Expansión e Interacción Cultural. Apéndice: el elemento púnico en la cultura talayótica (G. Olmo Lete, M.A. Aubet, ed.). Barcelona: 377-385. 
Prados Torreira, L. (1983): Los vasos de fondo alto de la cultura talayótica menorquina. Homenaje al profesor Martín Almagro Basch, vol. 2, Ministerio de Cultrura, Madrid: 205-218.

RÁmis RÁmis, J. (1817): Inscripciones romanas que existen en Menorca, y otras relativas à la misma sacadas de varios Escritores; suplidas, é ilustradas en quanto se ha podido, Imp. de Pedro Antonio Serra, (Edición facsímil, ed. Nura, Menorca 1995).

RAmón, J. (2012): La cerámica púnico-ebusitana en época tardía (siglos III-I a.C.). Cerámicas hispanorromanas II. Producciones regionales (D. Bernal Casasola; A. Ribera i Lacomba, eds.), Universidad de Cádiz: 583-617.

Rossello Bordoy, G.; Plantalamor Massanet, L.; Soberats Liegey, F. (1984): Excavaciones arqueológicas en Torre d'en Gaumes (Alaior, Menorca). El recinto de Taula y el sistema de recogida de aguas (campañas 1974, 1975 y 1977). Noticiario Arqueológico Hispánico, 19: 103-197.

SÁnchez LóPez, E.; Gutiérrez RodrígueZ, M.; Orfila Pons, M. (2013): Los asentamientos costeros de Menorca: el caso de Es Castellet (Calescoves, Alaior)., V Jornades d'Arqueologia de les Illes Balears (T. Riera, J. Cardell, coord.), Palma de Mallorca: 59-68.

SÁnchez LóPez, E.; Orfila Pons, M. (2015): Boles helenísticos con relieves a molde en el santuario de Calescoves (Menorca). Spal, 24: 273-249.

Sastre Moll, J. (1985): El vaso de fondo alto menorquín. Estudio tipológico y decorativo. Trabajos del Museo de Menorca 3.

ScHMID, S. G. (2006): Boire pour Apollon. ERETRIA XVI. Fouilles et recherches. École suisse d'archéologie en Grèce.

Veny Meliá, C. (1965): Corpus de las inscripciones baleáricas hasta la dominación árabe. Biblioteca de la Escuela Española de Historia y Arqueología en Roma 15, Roma.

Veny Meliá, C. (1982): La necrópolis protohistórica de Cales Coves, Menorca. Bibliotheca Praehistorica Hispana, 20, Madrid.

van Dommelen, P. (2011): Postcolonial archaeologies between discourse and practice. World Archaeology, 43-1: 1-6. DOI: 10.1080/00438243.2011.544883. 